\title{
Absence of lateral palpebral raphe in Caucasians
}

This article was published in the following Dove Press journal:

Clinical Ophthalmology

30 June 2009

Number of times this article has been viewed

\section{Lucy Goold' \\ Hirohiko Kakizaki ${ }^{1,2,3}$ \\ Raman Malhotra ${ }^{3}$ \\ Dinesh Selva'}

'South Australian Institute of Ophthalmology and Discipline of Ophthalmology and Visual Sciences, University of Adelaide, Australia; ${ }^{2}$ Department of Ophthalmology, Aichi Medical University, Nagakute, Aichi, Japan; ${ }^{3}$ Corneoplastic Unit and Eye Bank, Queen Victoria Hospital NHS Trust, East Grinstead, West Sussex, United Kingdom
Correspondence: Hirohiko Kakizaki Department of Ophthalmology, Aichi Medical University. Nagakute, Aichi 480-I 195, Japan

Tel $+8156 I 6233$ II (Ext. 218I)

Fax +8I 56I 637255

Email cosme@dI.dion.ne.jp
Abstract: Classical anatomical teaching reports the presence of the lateral palpebral raphe formed at the union in the preseptal and orbital parts of the orbicularis oculi muscle, or by the tendon adhering these to the underlying zygomatic bone. The lateral palpebral raphe has been shown to be absent in Asian cadavers. The current study uses both evidence from the anatomical dissection of five eyelids from three Caucasian cadavers, and histological assessment of the lateral canthus of 13 eyelids from seven Caucasian cadavers to illustrate the absence of the lateral palpebral raphe in Caucasian population.

Keywords: lateral palpebral raphe, orbicularis oculi muscle, Caucasian, cadavers

The presence or absence of the lateral palpebral raphe has long been a source of contention. A famous medical dictionary ${ }^{1}$ generally defines the "raphe" as "the line of union of two contiguous, bilaterally symmetrical structures". In addition, in the following part of the same dictionary, ${ }^{1}$ the "lateral palpebral raphe" is defined as "a narrow fibrous band in the lateral part of the orbicularis oculi muscle formed by the interlacing of fibers passing through the upper and lower eyelids". Traditionally, the lateral palpebral raphe has been thought to be the common tendon of the septal and orbital parts of the orbicularis oculi muscle, ${ }^{2}$ or the linear tendon of these parts attaching to the zygomatic bone. ${ }^{3}$ In contrast, there are also reports refuting the presence of the lateral palpebral raphe, suggesting that the orbicularis oculi muscle in the lateral part is continuous without tendinous intercalation. ${ }^{4}$ That the lateral palpebral raphe is formed purely by the interlacing of the muscle fibers is another opinion. ${ }^{5}$ Thus, there is no consensus regarding the lateral palpebral raphe.

The purpose of the present study was, therefore, to elucidate whether the lateral palpebral raphe existed in the Caucasian lateral canthus.

\section{Materials and methods}

We took both gross dissection and microscopic examination to elucidate whether lateral palpebral raphe existed or not, in which the decision was made by the single examiner (HK).

In gross dissection, five eyelids of three Caucasian cadavers ( 2 males: 1 right, 2 left; 1 female: 1 right, 1 left) aged from 81 to 89 years at death (average, 85.0 years), fixed in $10 \%$ buffered formalin, were examined. Westcott scissors were used to remove the lateral half of the upper and lower eyelid skin, and the orbicularis oculi muscle exposed. 
The connective tissue on the orbicularis muscle fibers was removed as completely as possible. The lateral part of the orbicularis oculi muscle was then examined to ascertain the presence or absence of the lateral palpebral raphe.

The method for removing the eyelid samples for the microscopic examination are stated elsewhere. ${ }^{6}$ Full thickness sections of eyelids fixed in $10 \%$ buffered formalin, from 13 postmortem eyelids of seven Caucasians ( 2 males: 2 right and 2 left; aged 78 and 88 years at death; 5 females: 5 right and 4 left; aged 80, 81, 90, and 101 years at death) were examined. Since some samples were broken during the microscopic specimen production, they were excluded. We made axial sections with $1 \mathrm{~mm}$ inferior from the lower eyelid margin, ${ }^{6}$ and included the part corresponding to the interlacing of the lateral orbicularis oculi muscle. Sliced specimens were dehydrated and embedded in paraffin, and cut into $7-\mu \mathrm{m}$-thickness sections, after which the sliced sections were stained with Masson trichrome. ${ }^{6}$ Microscopic photographs were taken with a digital camera system attached to the microscope (Moticam 2000; Shimadzu Rika Kikai, Tokyo, Japan).

All cadavers were registered with the University of Adelaide, and proper consents and approvals were obtained prior to use. Methods for securing human tissues were humane and complied with the tenets of the Declaration of Helsinki.

\section{Results}

In gross dissection, the lateral part of the orbicularis oculi muscle was continuous without tendinous intercalation in all specimens (Figure 1). A linear tendinous structure, namely the lateral palpebral raphe, ${ }^{1}$ was not identified in all five samples. Although an oblique union was seen in the pretarsal and preseptal portions of the orbicularis oculi muscle, the lack of any true linear union between the muscle fibers of the superior and inferior portions of the orbicularis oculi muscle belies its classification ${ }^{1}$ as the lateral palpebral raphe.

Microscopically, in all specimens, the orbicularis oculi muscle was also seen to be continuous without any tendinous interruption (Figure 2).

\section{Discussion}

The lateral palpebral raphe was not identified in the lateral part of the orbicularis oculi muscle in any of the samples examined. Whilst this has been previously documented in Asian samples, ${ }^{4}$ our findings appear to confirm its absence in Caucasian eyelids, although they were very old, and show concordance between these two racial groups.

The absence of the lateral palpebral raphe may have physiological significance. The interlacing of the superior

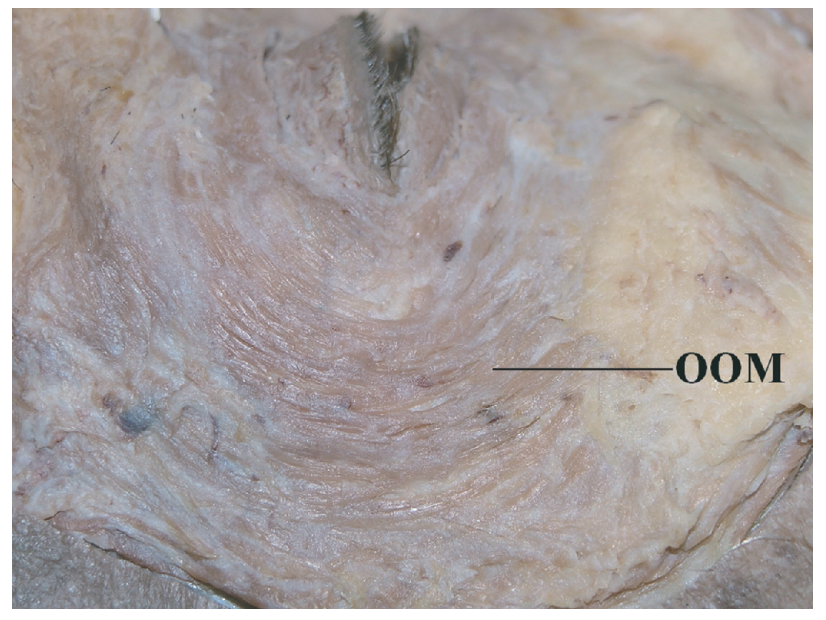

Figure I Macroscopical examination (left: cephalad, bottom: lateral). The lateral palpebral raphe is not identified in the lateral part of the orbicularis oculi muscle.The superior and inferior orbicularis oculi muscles were continuous without any tendinous intercalation between them. Central white tissue on the preseptal orbicularis oculi muscle is fascia.

Abbreviation: OOM, orbicularis oculi muscle.

and inferior orbicularis oculi muscle fibers may allow a moderate degree of medial movement of the lateral canthus with blinking, allowing the tear film to effectively spread medially for efficient corneal wetting. Some lateral fixation remains, however, to overcome the medial pull of the lateral canthus during blinking, maintaining the efficiency of the blinking movement.

Further studies may elucidate the true nature of the lateral portion of the orbicularis oculi muscle. Whilst this report documents the absence of the lateral palpebral raphe in the specimens examined, as drawbacks of the current study are the small sample numbers and the very advanced age

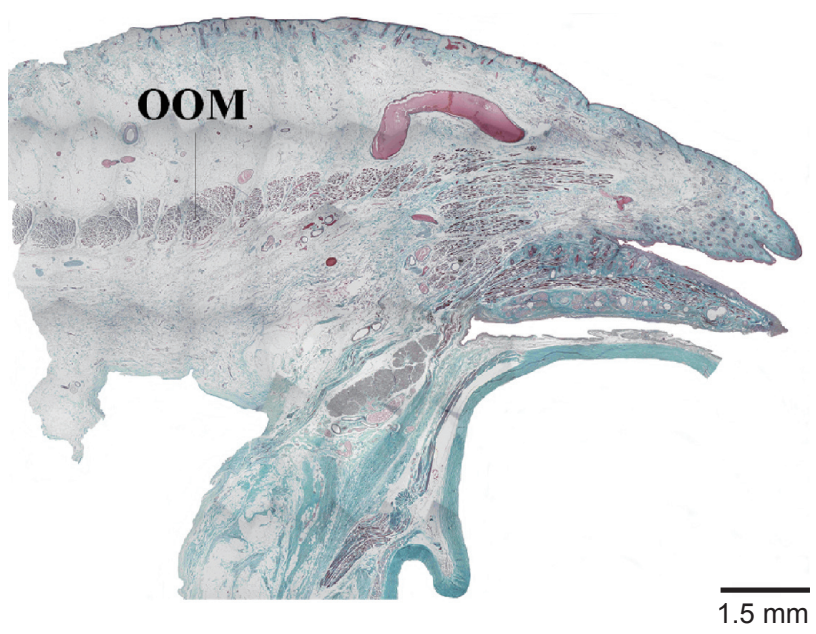

Figure 2 Microscopical sanple (left: lateral, up: anterior). The orbicularis oculi muscle continuously situated and the lateral palpebral raphe is not identified. Abbreviation: OOM, orbicularis oculi muscle. 
specimens, assessment of a larger number of specimens from a more widely variable age range may add to our understanding of this contested feature of eyelid anatomy.

\section{Disclosure}

The authors report no conflicts of interest or financial interest related to this manuscript.

\section{References}

1. Stedman's Medical Dictionary. 27th ed. Baltimore, MD: Lippincott Williams \& Wilkins; 2000. p. 1518.

2. Bron AJ, Tripathi RC, Tripathi BJ. Wolff's Anatomy of the Eye and Orbit. 8th ed. London, UK: Chapman and Hall Medical; 1997. p. 30-84.
3. Kikkawa DO, Lemke BN. Orbital and eyelid anatomy. In: Dortzbach RK, editor. Ophthalmic Plastic Surgery - Prevention and Management of Complications. New York, NY: Raven Press; 1994. p. 1-29.

4. Kakizaki H, Zako M, Nakano T, et al. No raphe identified in the orbicularis oculi muscle. Okajimas Folia Anat Jpn. 2004;81:93-96.

5. Whitnall SE. Anatomy of the Human Orbit and Accessory Organs of Vision (reprint). New York, NY: Robert E. Krieger Publishing Company Inc; 1979. p. 132.

6. Kakizaki H, Zako M, Nakano T, et al. Microscopic findings of lateral tarsal fixation in Asians. Ophthal Plast Reconstr Surg. 2008;24: $131-135$.

\section{Publish your work in this journal}

Clinical Ophthalmology is an international, peer-reviewed journal covering all subspecialties within ophthalmology. Key topics include: Optometry; Visual science; Pharmacology and drug therapy in eye diseases; Basic Sciences; Primary and Secondary eye care; Patient Safety and Quality of Care Improvements. This journal is indexed on

Submit your manuscript here: http://www.dovepress.com/clinical-ophthalmology-journal

\section{Dovepress}

PubMed Central and CAS, and is the official journal of The Society of Clinical Ophthalmology (SCO). The manuscript management system is completely online and includes a very quick and fair peer-review system, which is all easy to use. Visit http://www.dovepress.com/ testimonials.php to read real quotes from published authors. 